\title{
EXPERIÊNCIA ESTÉTICA NA SEMIÓTICA DISCURSIVA: PISTAS PARA LEITURA DE TEXTOS DE PROFESSORES SOBRE SUAS PRÁTICAS
}

\section{AESTHETIC EXPERIENCE IN DISCURSIVE SEMIOTICS: CLUES FOR READING TEACHERS' TEXTS ABOUT THEIR PRACTICES}

Gilvânia Maurício Dias de Pontes ${ }^{1}$ Analice Dutra Pillar ${ }^{2}$ 


\section{Resumo}

Abordar-se-á a concepção de experiência estética na Semiótica Discursiva, a partir da leitura dos enunciados que compõem a último livro produzido por Algirdas Julien Greimas, Da Imperfeição, e seus desdobramentos na obra de Eric Landowski. $O$ posicionamento sobre experiência estética, assumido pelos autores elencados, aponta para a indissociabilidade entre as dimensões sensíveis e inteligíveis em atos de leitura e produção de sentidos do ser no mundo.

\section{Abstract}

The conception of aesthetic experience in Discursive Semiotics will be approached from the reading of the statements that make up the last book produced by Algirdas Julien Greimas, " $D a$ Imperfeição", and its repercussions on the work of Eric Landowski., The positioning on aesthetic experience, assumed by the authors listed, points to the inseparability between the sensitive and intelligible dimensions in acts of reading and production of meanings of being in the world.

Palavras-chave: Semiótica Discursiva; Keywords: Discursive Semiotics; aestheestética; leitura. tics; reading.

ISSN: $2175-2346$

1 gilvaniapontes@hotmail.com

2 analicedpillar@gmail.com 


\section{Introdução}

Como abordar a experiência estética de professores enunciada em seus textos escritos? Essa foi uma das questões metodológicas que emergiram quando do ensejo de investigação da presença das experiências estéticas de professores em práticas docentes. Este artigo foi organizado a partir de uma pesquisa que teve como principal objetivo investigar a relação entre experiências estéticas e práticas docentes com linguagens artísticas, narradas em memoriais produzidos professores da educação da infância, em um curso de especialização. A etapa da pesquisa a qual este artigo está relacionado diz respeito à construção de aportes de leitura que possibilitassem a identificação de experiências estéticas em textos escritos por professores.

A tematização de uma dimensão de apreensão de conhecimento, cuja natureza primeira parece pertencer à ordem do sensível, envolveu o diálogo com teóricos, que se debruçaram sobre a produção de significação, que consideram o sujeito sensivel atuando para significar sua presença no mundo. A enunciação, sob a forma de escrita, é, ao mesmo tempo, sensível / inteligivel. O produtor da enunciação é um sujeito sensível e o enunciado é uma construção em que se entrelaçam essas intrincadas facetas do conhecer. $O$ contagio entre essas dimensões de ser e estar no mundo foi abordado na obra do filósofo Maurice Merleau-Ponty (2000; 1999) e retomada por Algirdas Julien Greimas (2002; 2017) para propor um projeto de semiótica. Nesse artigo enfatizam-se as reflexões de Greimas sobre experiência estética e seus desdobramentos nas pesquisas de Eric Landowski.

\section{Da Imperfeição: o livro do qual se fala, nos fala?}

Da Imperfeição é a última obra individual de Greimas. O livro, publicado na França em 1987 e no Brasil em 2002, reeditado em 2017, é, como afirma Ana Claudia de Oliveira, no prefácio da edição brasileira de 2002, um convite a uma reflexão sobre o modo de presença da estética na cotidianidade e, em 2017, ela afirma ser esta obra um testamento de desenvolvimento teórico para novos semioticistas e para o público de outras áreas interessado na investigação de processos de significação, seja na análise em textos ou de práticas da vida cotidiana.

Greimas busca, na fenomenologia de Merleau-Ponty, a noção de sujeito sensivel incrustado no mundo, feito do mesmo estofo das coisas, carne do mundo, sujeito que pode experienciar o entorno como corpo reflexionante em uma relação estesiologica com aquilo que Ihe desafia a produzir sentido. Em Da Imperfeição, ele traz excertos de textos literários para enfocar a dimensão sensivel da significação, integrando às análises semióticas a problemática dos fenômenos de significação em sua dimensão estética.

Nessa obra, a interconexão entre linguística, antropologia e fenomenologia, que marca a arquitetura teórica da semiótica discursiva, é ampliada e revitalizada com a abordagem da dimensão sensivel - o que remete, especialmente, às origens fenomenológicas do projeto semiótico. O foco de estudo da semiótica discursiva continua a ser os modos de significar, mas, a partir dessa obra, a semiótica passa à reflexão sobre o modo de presença da estética na vida humana.

Teixeira (2002, p. 258), em uma resenha sobre o livro, comenta: "Desenvolve-se no livro a reflexão acerca dos mecanismos de produção do sentido, mas não do sentido de um texto, nem mesmo dos textos estudados. O que quer o teórico é relacionar teoria e vida, literatura, acontecimento estético e aventura humana". O livro nos convida a vivenciar os encontros estéticos das personagens de papel - ritmos de um tempo criado pelos autores e enfocados 
por Greimas. Ao leitor de Da Imperfeição cabe o estabelecimento de novos ritmos e outras narrativas que possam ir além do livro.

Da Imperfeição está dividido em duas partes: A fratura e As escapatórias. Na primeira parte, os acontecimentos estéticos, evocados por Greimas, a partir da leitura dos textos de $M$. Tournier, I. Calvino, R. M. Rilke, J. Tanizaki e J. Cortázar ${ }^{1}$, falam sobre a experiência sensível no encontro entre sujeitos e objetos, tomando a forma súbita de uma irrupção do sentido e do valor. Num primeiro momento, uma falta de sentido - suspensão da vida cotidiana - à espera do inesperado; num segundo tempo, uma aparição súbita e deslumbrante que faz o sujeito entrever para além da banalidade das aparências, um mundo outro, para, em um terceiro momento, voltar à cotidianidade. Esse percurso é feito em três instâncias; de um lado, está a experiência estética e, do outro, o cotidiano do qual o sujeito emerge somente um instante para, logo em seguida, voltar a mergulhar nele. A descrição dos acontecimentos estéticos abarca, conforme Landowski (2002), o que precede o encontro entre sujeito e objeto (disjunção ${ }^{2}$ ), o próprio encontro (momento de união - estesia ${ }^{3}$ ) e o que segue (retorno à disjunção), distinguindo efeitos de sentido produzidos em cada um deles.

Neste livro, Greimas escolhe, para análise, textos em que os autores assumem diferentes concepções de estética, mas narram encontros entre sujeitos e objetos nos quais o aspecto estésico é reiterado. Assim, Greimas acaba por esboçar uma teoria semiótica do estético cujo componente fundamental para a significação dos eventos é a estesia. Nos textos, o sujeito sensível habita o mundo em relação com as coisas e/ou com as manifestações da arte. Unem-se a ele outros sujeitos/objetos como extensão dele mesmo. O sujeito é corpo vidente em movimento para significar a experiência vivida, como na experiência de Robinson Crusoé, no texto de Tournier, que é retomada por Greimas em $\mathrm{O}$ deslumbramento. Greimas refere que:

\begin{abstract}
Robinson - o de Michael Tournier -, que até esse momento havia conseguido ordenar sua vida segundo o ritmo das gotas de água que caíam uma a uma de uma clepsidra improvisada, encontrou-se de repente despertado pelo 'silêncio insólito' que lhe revelou 'o ruído da última gota a cair na bacia de cobre', Constatou então que a gota seguinte 'renunciando decididamente a cair', chegou mesmo a 'esboçar uma suspensão do tempo. Em seguida, ele levantou-se e foi colocar-se na moldura da porta. O feliz deslumbramento que o envolveu fê-lo vacilar e obrigou-o a encostar o ombro a alisar (GREIMAS, 2002, p.24).
\end{abstract}

Conforme o autor, Robinson é capturado pelo barulho da gota que cai, seguido do silêncio da gota que teima em não cair ${ }^{4}$, supressão do ritmo do cotidiano que o lança a outro estado de entrecruzamento, um estado de conjunção com a coisa mesma que até então não se faz nomeada por ele. O personagem é tomado pela audição e, em seguida, pela visão da gota pendente. Nesse momento, vê o invisível do visível "uma outra ilha atrás daquela onde penava solitariamente...mais fresca, mais quente, mais fraterna..." (GREIMAS, 2002. p25). Tal evocação de um lugar ideal é, para Greimas, uma marca do classicismo de Tournier quando este opta por enfatizar o aspecto eidético, referente à forma.

\footnotetext{
1 Sexta-feira ou os limbos do Pacífico, de Tournier; os contos O guizzo, de Calvino, A continuidade dos parques, de Cortázar; o poema Exercícios ao piano, de Rilke; O elogio da sombra, de Tanizaki

2 Denomina-se junção à relação que une o sujeito ao objeto, isto é, a função constitutiva dos enunciados de estado. [...]A posição do objeto - valor no percurso sintático permite distinguir, por exemplo, entre disjunção (o objeto que jamais foi possuído) e não conjunção (que pressupõe, sintagmaticamente, que o objeto já tenha sido possuído) (COURTÉS; GREIMAS, 2008, p. 279)

3 União de sujeito-objeto de tal forma que não se sabe mais quem é sujeito e quem é objeto. Como a mão que toca a mão que é tocada, resaltada por Merleau-Ponty.

$4 \quad$ Para os gregos, a apreensão estética se dá pela atividade privilegiada da visão e da audição, sentidos que estariam mais próximos da essência imaterial da alma e, dessa forma, seriam capazes de aproximar o humano da beleza. (LACOSTE, 1997)
} 
A nostalgia de perfeição é desencadeada em Robinson quando da interação com a gota, transformada por ele em objeto estético. O movimento da gota também é analisado por Greimas como marca da concepção estética da época clássica assumida por Tournier - uma gota que teima em cair e assume um perfil piriforme, mas volta à forma esférica, retorno de uma forma barroca a uma forma perfeita - modelo de harmonia e beleza para o classicismo.

Greimas enfatiza: Robinson, o de Tournier, indicação de seguir na análise a partir das escolhas estéticas de Michael Tournier. A obra é uma recriação do Robinson Crusoé, de Daniel Defoe, publicada na Inglaterra, em 1719. O texto de Tournier é atravessado por citações filosóficas, como no início do romance, quando o autor apresenta seu Robinson aos enunciatários:

[...] O capitão van Deyssel debruçou-se por sobre a barriga para pousar o baralho na frente de Robinson. - Corte e vire a primeira carta - disse-lhe. Deixou-se depois tombar na poltrona e tirou uma baforada do cachimbo de porcelana. - É um demiurgo - comentou. - Um dos três arcanos maiores mais importantes a uma bancada. Representa um saltimbanco de pé. Isso significa que em você existe um organizador. Ele luta contra um universo em desordem, que se esforça por dominar com meios ocasionais. Parece consegui-lo, mas não devemos esquecer que este demiurgo é também saltimbanco: a sua obra é ilusão, a sua organização é ilusória (TOURNIER, 1990, p. 5).

O demiurgo é uma figura da filosofia platônica que fabrica os utensílios que devem ser utilizados pelos homens. Esse artesão produz perseguindo a ideia, a essência do ser. Assim, o artesão não é o criador, apenas subordina seu trabalho à ideia. Sua produção é guiada pela mímese - imitação das formas ideais. "A Ideia é o que, por sua presença, faz uma coisa ser o que é (...). O ser definido como Ideia, é permanente e opõe-se, por conseguinte, à mudança e ao devir" (LACOSTE, 1997, p. 10-11). Como foi enunciado no texto, o demiurgo de Tournier é também um saltimbanco - um organizador do mundo, cuja obra não passa de ilusão. Referência do autor à criação humana como mímese - atividade produtora de que Robinson é demiurgo, imitação de um mundo de formas ideais.

$\mathrm{Na}$ enunciação do destino da personagem, no início do livro, Tournier faz referência ao Mito da Caverna de Platão - retirar-se do mundo sensível (ilusório) para contemplar o mundo real - mundo das ideias, fonte original da Verdade e do Belo:

[...] Ora vejam! Que lhe dizia eu? É o Eremita. O guerreiro tomou consciência da própria solidão. Retirou-se para o fundo de uma gruta para reencontrar a sua fonte original. Mas, mergulhando assim no seio da terra, cumprindo esta viagem ao fundo de si próprio, tornou-se outro homem. Se alguma vez deixar esse retiro, notará que a sua alma monolítica sofreu profundo golpes (TOURNIER, 1990 p.6).

Assim, é possível perceber, na narrativa de Tournier, relações intertextuais com a filosofia e, especialmente, com uma concepção clássica de estética. No entanto, quando da enunciação da experiência estética do personagem Robinson, há a referência à estesia que o envolve para significar aquele momento; estesia que o leva para um mundo ideal.

Em O guizzo, o Sr. Palomar - personagem de Ítalo Calvino - caminhando numa praia deserta - depara-se com uma moça deitada com seios nus. Tal evento desencadeia apreciações que envolvem várias significações do olhar: o seio é um objeto estético agradável ao olhar, mas também incita reflexões numa dimensão moral e social. Palomar, imerso na diversidade dessas significações, questiona-se sobre como agir diante do seio nu, o que - obriga a "voltar várias vezes, sobre seus passos para testar as diferentes hipóteses que formula sobre o bom uso do olhar diante desse objeto insólito" (GREIMAS, 2002, p.31). Para 
Greimas, Calvino tece dois retratos do seio nu, duas possibilidades de apreciação do objeto estético - o seio como objeto em si, deslocado de seu contexto cultural e erótico, e o seio como parte do corpo feminino, com as implicações éticas que se podem atribuir à visão do seio nu. O Sr. Palomar ora tenta não olhar diretamente para o seio destinando a trajetória do seu olhar ao vazio, ora atenta para os diversos elementos do seu campo visual, encarando o seio como mais um elemento da paisagem. Assim, a personagem de Calvino é tomada por dois modos de apreensão estética. Acrescenta Greimas que "a estética de Calvino remete à concepção husserliana da percepção ${ }^{5}$, na qual as estruturas receptivas do sujeito se projetam adiante das Gestalten desejosas de com elas se reunir" (GREIMAS, 2002, p.34). A visão do seio nu inquieta o olhar ordinário de Palomar que é desafiado a produzir significações diferentes para o objeto estético que o desafia. Tanto o Sr. Palomar quanto o objeto estético - seio não contêm em si o sentido; é na relação entre eles que a significação se faz presente. "O estremecimento, como concretização da estesia, encontra-se, pois, distribuído tanto sobre o sujeito quanto sobre o objeto e marca o sincretismo dos dois actantes..." (GREIMAS, 2002, p. 37). Esse estremecimento visual remete também à tatilidade; os olhos de Palomar tocam a pele da moça estendida na areia. Para Greimas, a apreciação estética que Calvino atribui a Palomar vai do reino da beleza à república do gosto 6 .

Em O odor do Jasmim, Greimas analisa o poema Exercícios ao piano, de Rilke. Nele uma jovem que toca piano é subitamente tomada por aromas de jasmins. O primeiro movimento é de remeter-se ao parque que está além de sua janela. Num segundo movimento, a jovem refuta o odor de jasmim; acha que a faz doente. O poema se presta a todas as análises, diz Greimas, para, em seguida, explicitar dois argumentos estéticos de leitura do poema: "no plano do enunciado, a experiência da jovem diante do 'parque', no plano da enunciação (enunciada), a apreensão, pelo recurso do devaneio, das formas organizadas de nosso imaginário" (GREIMAS, 2002, p. 42-43). Devaneio e imaginário palavras/marcas no texto que são significativas de uma escolha estética que intenciona, por meio do jogo de palavras, provocar sensações no enunciatário, que o leve para além do texto.

Em A cor da obscuridade, Greimas analisa um texto de Junichiro Tanizaki, parte da obra Em louvor da sombra (1933). Nesse livro, Tanizaki faz uma abordagem estética e cultural do valor da sombra na tradição oriental e, mais especificamente, para os japoneses antigos.

Descreve sensações contextualizando experiências estéticas do cotidiano oriental desencadeadas, especialmente, pela presença da obscuridade em diferentes ambientes. Ao contextualizar tais experiências, Tanizaki narra a relação sujeito-objeto que significa determinados ambientes. No livro Em louvor da sombra, no parágrafo anterior ao do texto analisado por Greimas, Tanizaki se refere à brancura (maquiagem) da pele das senhoras japonesas em contraste com a obscuridade do ambiente e a maquiagem que enegrece os dentes - uma composição entre o elemento humano e o ambiente em que a obscuridade desempenha papel importante.

\footnotetext{
$5 \quad$ Um exemplo desse movimento nos é oferecido por Husserl (2005, p. 124) quando trata da percepção sobre a cidade de Colônia por alguém que já tem algumas informações sobre a cidade: "O protótipo de interpretação da relação entre o significar e o intuir seria assim a relação entre a significação própria e as percepções correspondentes. Quem conhece pessoalmente Colônia e possui, por conseguinte, a verdadeira significação própria da palavra Colônia, encontra, em cada uma das vivências de significação atuais, um exato correspondente da futura percepção confirmadora. Não se trata propriamente de uma réplica da percepção, como no caso da fantasia correspondente; mas, tal como a própria cidade está (presumidamente) presente na percepção, assim também, conforme o que foi exposto acima, o nome próprio Colônia, na sua significação própria, visa 'diretamente' esta mesma cidade, ela própria, assim como é".

6 Para Ferry (1994, p. 31), foi no século XVII que o termo 'gosto' adquiriu pertinência na designação de uma faculdade capaz de distinguir entre o belo e o feio e apreender pelo sentimento (aisthêsis) e também foi a partir da representação de tal faculdade que ingressamos definitivamente no universo da estética moderna. A personagem Palomar se vê diante de alguns condicionantes da apreensão estética - inicialmente condicionantes relativos à forma do objeto; e num segundo momento, um outro olhar, surgem os questionamentos sobre a relação moral que circunda aquela situação de apreensão do objeto.
}

Gilvânia Maurício Dias de Pontes 
No texto escolhido por Greimas, Tanizaki faz uma apreciação da sombra em simultaneidade com a luz de uma chama. A sombra se torna o objeto estético a ser questionado, mas, nesse caso, só o é porque há a quebra de continuidade quando da colocação de uma vela na sala. No entrecruzamento entre luz e sombra, emerge, na narrativa, a pergunta sobre qual a cor das trevas sob a luz de uma chama. A abordagem estética do autor japonês coloca os objetos em coexistência, produzindo a experiência estética com a obscuridade. A experiência estética envolve sensações contextualizadas em que os objetos atuam como sujeitos a desencadear os processos de significação.

No texto de Julio Cortázar, A continuidade dos parques, o objeto estético é um texto literário com o qual um sujeito entra em contato. “É a história de um grande senhor, homem de negócios e esteta em certas ocasiões, que empreende, de maneira intermitente, a leitura de um livro e penetra por etapas num novo objeto ficcional" (GREIMAS, 2002, p. 56). O homem, recostado em sua poltrona favorita, sente a textura desse objeto, e, enquanto lê, afasta-se paulatinamente daquilo que o rodeia, o prazer estético emerge desse distanciamento. Tomado pelo texto, em conjunção com esse objeto estético literário, o homem parece se inserir na narrativa, ou, como ressalta Greimas, a eficácia do objeto literário - ou mais geral estético está na dissolução assumida pelo sujeito - na morte obrigatória do leitor-espectador. Morte ou vida em êxtase, a aestesis sonhada.

A dissolução do leitor no texto, sua inserção na narrativa por meio da estesia provocada pela leitura, aponta para consideração da estética da recepção ${ }^{7}$ como teoria que organiza as intenções do enunciador do texto. A organização textual considera a relação entre autor, obra e leitor no processo de significação.

A análise de Greimas dos textos literários, enfatizando a experiência estética de sujeitos de papel aguça nosso olhar para ir além das classificações sobre estética, sem esquecer que elas estão presentes na organização dos textos por seus autores. A reiteração da estesia como componente comum a todos os encontros selecionados por Greimas aponta que é necessário considerar tanto os significados acerca da estética quanto a ação dos sujeitos no momento da apreensão estética. No caso dos textos escritos, os sujeitos podem presentificar tanto suas concepções de estética quanto relatar encontros estésicos que lhes foram significativos. Para compreender as dimensões envolvidas na escrita pelos autores professores, quando se colocam como sujeitos de papel em seus memoriais, seguiremos com a leitura sobre Da Imperfeição, inserindo o ponto de vista de alguns comentadores dessa obra, assim como os desdobramentos que a abordagem estética de Greimas produz nas pesquisas de Eric Landowski. Para Fabri (2002, p. 99), ao optar pelo estésico - pelo componente afetivo e sensível da experiência cotidiana - Greimas retomou a síntese filosófica de Merleau-Ponty sobre a percepção e a ampliou no sentido da interrogação especulativa sobre o sensível. O encontro do sujeito com o objeto se dá pelos canais sensoriais por meio dos quais o sujeito vivencia o acontecimento estético.

É o corpo sensível que significa, como modo de existir no mundo. Entretanto, Greimas, diferente de Merleau-Ponty, valoriza o háptico, contra o ótico - enfatiza o olfato e o tato muito mais do que o mais intelectual dos sentidos, a visão. Para Greimas, o sujeito tátil, tende a fundir-se com o objeto e, nesse momento, o juízo estético deixa de ser um veredito para tornar-se íntima comunicação entre sujeito-objeto.

7 Teoria de análise da leitura formulada da década de 1960, especialmente por Hans Robert Jauss e Wolfgang Iser, defende que a recepção do texto artístico ou cultural envolve a relação entre autor, obra e leitor. Desse modo, texto não é criado, exclusivamente, pelo artista, mas pela relação estabelecida entre o objeto e o receptor ou leitor. Ver ISER (1996; 1999). 
A segunda parte do livro Da Imperfeição é dedicada a discutir as situações produzidas para romper com a rotina do cotidiano. Greimas discute a possibilidade dos encontros estéticos numa nova configuração de relação entre sujeito-objeto, ao mesmo tempo, sensível e inteligível.

Em Imanência do sensível, Greimas retoma a emergência da apreensão estética como parte da experiência vivida. Afirma o autor que Friedrich Schiller foi precursor na defesa do ideal da arte pela arte que influenciou arte e literatura a partir do século XIX. Passa-se a conceber a apreensão estética enquanto percurso particular dos sujeitos, como em alguns textos escolhidos por Greimas na primeira parte do Da Imperfeição. Sob esse lastro, a estética passa a ser vista como acontecimento repentino, fratura no cotidiano da vida que está aberta a diversas interpretações. A apreensão estética envolve o desencadeamento de sensações em que "o espaço organizado da percepção se converte em uma extensão biomática ${ }^{8}$ em que todas as espécies de sinestesias são possíveis" (GREIMAS, 2002, p. 70). A interligação entre as sensações, sincretismo sensorial, é enunciado por Greimas como um enriquecimento da comunicação do sujeito com o mundo. No capítulo Uma estética exaurida, Greimas nos convida a esquecer, momentaneamente, os acontecimentos extraordinários que impelem o sujeito à conjunção com o objeto em raros momentos para lançar olhares sobre as práticas cotidianas da estética. Ele traz para análise a cultura vestimentar, enfatizando os exercícios das práticas vestimentares femininas em suas diferentes dimensões. Para Greimas (2002, p. 75), "vestir-se é coisa séria e toda a inteligência sintagmática é empregada neste ato: eis uma sequência de vida 'vivida' como uma sucessão ininterrupta de escolhas e que conduz pouco a pouco à construção de um objeto de valor". Escolhe-se a roupa com várias intencionalidades funcionais: adequação às condições atmosféricas - conforto; por pressão social - previsão do ambiente ou das circunstâncias. Aqui entra em cena o juízo de gosto em conformidade com o saber- viver, educação e ética.

Há na escolha da vestimenta, também, o componente passional - desejo de agradar - que está relacionado à imagem que uma pessoa tem de seu corpo, à imagem que o outro tem dela ou àquela que ela quer fazer chegar ao outro.

Outra prática que envolve a cultura vestimentar é a do exercício de olhar vitrinas. As vitrinas são intencionalmente organizadas para capturar o olhar pela promessa de um corpo imaginariamente vestido. A prática vestimentar, nessa situação, envolve outra grade de leitura, pois, quando uma pessoa se propõe a vestir determinada peça, geralmente, guia suas escolhas por fatores externos, no caso do olhar para as vitrinas, "os elementos de informação submetidos ao julgamento são de ordem figurativa - linha, cores, gestos, atitudes - mas requerem ser avaliados e dotados de significados de ordem conceitual: simplicidade, elegância, refinamento" (GREIMAS, 202, p. 77). As grades de leitura socioestética remetem às projeções passionais, como na pintura do Renascimento. $E$, no que se refere ao domínio do gosto, parecem constituídas de saberes do grande século das Luzes, tais como estilo, originalidade e estilo de vida. Alerta o autor que a estesia corpo-roupa da qual tratou pode se tornar anestesia se tomada como 'uso e usura', isto é, como banalização dos usos sociais das vestimentas. Dessa forma, o autor nos alerta para importância do olhar leitor que produz sentidos para as situações; é esse olhar que faz com que o processo de significação possa ir para além do uso e usura.

8 Biomática entendida como um sistema que diferentes sinestesias são evocadas, isto é na apreensão dos objetos os diferentes sentidos atuam em conjunto para produzir a significação. 
Em A espera do inesperado, Greimas toma a ideologia da ação pela ação, comum aos modos de agir contemporâneos, como ponto de partida para reflexão sobre significação estética. Questiona ele sobre como superar o umbral da insignificância e sobre como integrar valores transcendentes aos comportamentos cotidianos dos sujeitos. Como ressemantizar objetos gastos que rodeiam as relações intersubjetivas? "Entre as práticas do gosto socializado, que conduzem à usura das categorias estéticas e o grande evento, que talvez acontecerá, existirá um caminho pessoal por traçar, um caminho para a esperança?" (GREIMAS, 2002, p. 86). Ou, como o próprio Greimas afirma, trata-se da vida cotidiana e dos diferentes meios de nela introduzir fraturas, ou de transformar a espera do inesperado numa espera esperada do inesperado.

Landowsky (2017) reitera a relevância do livro Da Imperfeição para os semioticistas e expõem o ensejo de divulgá-lo além dos círculos familiares da Semiótica. O autor justifica tão intenção ao afirmar que o livro trata de uma prática que concerne a todos, a busca do sentido. Prática que, em Da Imperfeição, não se limita ao estudo de formas desencarnadas, apenas inscritas na realidade de papel, mas do sentido em ato, da experiência vivida considerando a inseparabilidade entre a ordem do sensível e a do inteligível.

\section{Conclusão: das pistas para leitura de narrativas de professores}

A abordagem greimasiana de experiência estética ofereceu algumas sínteses que favoreceram leitura dos memoriais de professores, especialmente porque se buscava nesses textos a narrativa de encontros estéticos que pudessem inspirar a organização de práticas pedagógicas com as linguagens das artes. Em Da Imperfeição Greimas enfatiza a estesia nos momentos de apreensão estética, ao entrar em contato com formantes estéticos há um envolvimento corporal do sujeito que significa o evento do qual participa. Dessa maneira, o juízo estético é produzido a partir do contágio entre sujeito e objeto. Enquanto contagio produzido na relação entre sujeito e objeto, o juízo estético não é remetido às categorias de beleza formuladas a priori. Ele, o juízo estético, é apresentado por Greimas como um percurso particular do sujeito leitor de mundo.

Diante disso, na leitura dos memoriais de formação foi fundamental considerar a narrativa de momentos de encontro dos professores com objetos estéticos, experiências que Ihes provocaram estesias. A descrição e reflexão sobre esses encontros, nos memoriais, que ocorre de forma particular e contextualizada, são demonstrativas da valoração que o sujeito atribui àquela experiência e da relação que estabelece com a sua formação.

Greimas, assim como Merleau-Ponty, salienta o aspecto interacional da apreensão estética de mundo, trazendo a discussão de estética para as práticas cotidianas em que sensível e inteligível entretecem sentidos para o entorno. Nos memoriais de formação as experiências estéticas fazem parte de eventos do cotidiano, que, também, são analisados pelos autores como contendo possíveis conteúdos de situações de aprendizagem das artes na escola.

A referência feita por Landowski à inter-relação entre Inteligível/sensível na superação das fronteiras entre sentir - conhecer/entender tornou-se imprescindível para a tessitura da interpretação para o diálogo entre as experiências estéticas dos professores e a organização de práticas docentes com linguagens artísticas. A escrita de situações que marcaram os professores, como memória de infância, tornou visível algumas sensações, que foram descritas em suas vinculações afetivas e culturais e, em outros momentos, se fizeram presentes influenciando a escolha de conteúdos e metodologias quando da organização de práticas docentes com linguagens artísticas. 
Para Landowski (2002, p. 128), a obra Da Imperfeição traz, para a pesquisa semiótica, noções de estética e de estesia, consideradas não apenas no plano da sensibilidade, mas também na relação com o surgimento do inteligível. A semiótica, a partir de Da Imperfeição, passa a se preocupar como o par inteligível/sensível na aproximação entre sujeito-objeto, pretendendo superar as fronteiras entre as dimensões do sentir - conhecer/entender - para dar conta da emergência e do modo de existência do sentido em relação ao domínio do estético, pois, como reflete Landowski (2002, p. 129):

[...] seria vão comprometer-se por demasiado tempo com um trabalho de refinamento das distinções e das definições que nos faria esquecer o que temos que dar conta, ou seja, do fato de que sobre o plano que nos interessa particularmente - o do 'vivido' -, o inteligível e o sensível aparecem dificilmente separáveis um do outro, dado que a experiência chamada 'estética' raramente convoca um deles sem mobilizar também o outro.

Landowski observa que Da Imperfeição dá margem a duas interpretações para a teoria estética. A primeira aborda a aparição do estético como um evento acidental. $O$ acidente estético insurge no cotidiano de um sujeito, que se encontra imerso na rotina, quando surge algo inesperado. Há uma ruptura súbita, independentemente da sua vontade, a qual modifica sua maneira de ser e de ver o mundo, impondo-lhe uma comoção estésica que revela, para ele, outro sentido. Em seguida, acontece um retorno a um estado semelhante ao do começo, um estado novamente dessemantizado. Como o acidente estético, independe da vontade do sujeito; este buscará revivê-lo e ficará, então, à espera do inesperado. Landowski salienta que essa leitura da experiência estética pauta-se pela disjunção entre sensível e inteligível, uma vez que contrapõe dois modos distintos de estar-no-mundo: a plenitude dos sentidos no momento da fratura e o vazio em que o sujeito é lançado no momento seguinte. Essas dimensões da experiência vivida são concebidas como independentes e incompatíveis. No que toca ao sentido, tanto sua aparição acidental quanto sua presença efêmera ocorrem como explicação de sua ausência na normalidade das experiências cotidianas.

A segunda leitura das noções de estética e estesia em Da Imperfeição é menos acidentalista e mais construtivista. Sem deixar de considerar as descontinuidades, 0 inesperado coloca outra problemática em termos de intencionalidade e progressividade. O sentido, antes acidental e independente da vontade do sujeito, passa a ser analisado nos comportamentos cotidianos e é possível de ser buscado pelo sujeito por meio de um fazer estético, que Landowski descreve como uma sucessão ininterrupta de escolhas que conduz pouco a pouco à construção de um objeto de valor. Assim, 0 valor estético "não aparece mais como objeto providencialmente dado ao sujeito, mas como uma realidade que terá de ser construída por ele" (LANDOWSKI, 2002, p. 138).

As duas interpretações para teoria estética, identificadas por Landowski em Da Imperfeição, evidenciaram-se nos memoriais de formação como movimentos que poderiam ser complementares, e como dimensões de leitura das experiências estéticas. Há nos textos a narração de eventos acidentais que tomam os professores, como fratura do cotidiano, instigando-os à produção de novos sentidos e há a narrativa de momentos em que evidenciavam a intencionalidade e progressividade dos encontros estéticos.

Sob a ótica da construção de sentido estético, faz-se necessário pôr em relação a imediaticidade da experiência sensível - por natureza pré-discursiva - e o projeto de 
inteligibilidade dos fenômenos. Diante desse desafio, aconselha Landowski (2002, p. 141): "[...] para quem quiser abordar semioticamente as 'experiências estéticas' que os sujeitos históricos reais vivem', será necessário aplicar-lhes os mesmos princípios de indagação que servem para abordar os demais objetos, considerados mais próximos ao dizível".

Sobre a aproximação entre o sensível e o dizível ou o desafio de dizer do sensível, Landowski alerta para as armadilhas das análises que promovem uma hierarquização entre o sensivel e o inteligível, colocando o sensível na posição de objeto - povoado por aqueles que o vivem, sujeitos históricos reais - tendo sobreposto a ele o plano do inteligivel - reservado para um sujeito do saber, que não vive aquilo do qual se ocupa. Salienta que Da Imperfeição acaba com esse ascetismo quando postula um sujeito que é, ao mesmo tempo, sensivel e cognoscível, cujo fazer estético se desenvolve, simultaneamente, nesses dois níveis.

Os professores, em seus memoriais, produziram respostas pessoais para o desafio de dizer do sensível sem que houvesse sobreposição do plano do inteligível sob o sensivel; e como leitora de seus textos foi preciso abandonar a hierarquização e sobreposições para considerar que aquele que escreve sobre suas experiências estéticas é sujeito do sentir/saber, que produziu, também, formas de dizer do sensível.

Outra pista importante, para a leitura das experiências estéticas presentes nos memoriais de formação, foi fornecida por Landowski em suas pesquisas sobre regimes de interação e sentido. Landowski escolhe voltar sua atenção para as condições de emergência da significação na dinâmica dos discursos e das práticas. No texto Modos de presença do visível (LANDOWSKI, 2004), o autor aborda os processos de emergência do sentido experimentado, isto é, busca a emergência da significação no momento da interação entre sujeito e objeto. Landowski relaciona os processos de significação aos princípios de leitura inerentes à experiência sensível. Enfatiza ele que, nessa interação entre sujeito e objeto, ocorre a produção do sentido sentido, isto é, sentido como sensação e sentido como significação. A forma como o mundo se torna presente em sua dimensão sensivel para um sujeito está relacionada aos significados que serão produzidos por ele. Questiona sobre "como a apreensão de um sentido que seria somente experimentado poderia engendrar a produção de um saber" para acrescentar que:

[...] De fato, o regime de presença no mundo em que vivemos comanda o regime de sentido segundo o qual o mundo pode significar para um sujeito. Mas, em contrapartida, o mundo-objeto é ele mesmo um mundo sensível cujo modo de presença em relação a nós condiciona a maneira como o vivemos e, por conseguinte, nosso grau de disponibilidade diante dele enquanto lugar de emergência potencial do sentido. A análise das 'formas de vida' que os sujeitos adotam, ou seja, a explicitação de seus regimes de presença no mundo, não é, portanto separável de uma análise que alcance correlativamente as propriedades de ordem estésica imanentes aos objetos (discursos, ou imagens, seres animados e coisas), na falta da qual seria impossível dar conta dos diversos modos como eles se dirigem a nós, e nos transformam no que em contato com eles nos tornamos (LANDOWSKI, 2004, p. 106).

Até a publicação de Da Imperfeição, os semioticistas concentravam-se na análise das interações que poderiam se caracterizar em termos de gramática narrativa, a qual 
procurava descrever e examinar as relações dos sujeitos com os objetos de valor, que circulavam entre eles. A posição do objeto determinava por junção as variações de estados que afetavam os sujeitos - estados eufóricos (conjunção), estados disfóricos (disjunção). A lógica pretendida era a de entrar em conjunção com o objeto de valor.

As produções dos semioticistas, após a publicação de Da Imperfeição, apontam para interações sensíveis entre sujeito e objeto. Influenciados pela fenomenologia de Merleau-Ponty, em que o mundo se apresenta como uma totalidade que faz sentido, os semioticistas se voltam para a análise do sentido que emerge no plano do vivido.

No intuito de abordar a análise do sentido que emerge do plano do vivido, Landowski reconhece a existência do regime de sentido da união. Um regime de sentido alicerçado na copresença sensível dos actantes face a face ou corpo a corpo.

No regime de junção, circulam entre os sujeitos objetos que têm um valor já definido, enquanto, no regime de união, os actantes entram, estesicamente, em contato e é na sua copresença interativa que se constrói a produção de sentido e a criação de valores novos. O regime de junção coloca como questão o ter ou não ter o objeto de valor enquanto o regime de união aborda questões referentes a ser e estar no mundo.

Para Landowski (2005, p. 19), os modelos de junção e união se constituem em abordagens complementares.

Ao lado da lógica da junção entre sujeitos e objetos, que fundamenta a abordagem dos fenômenos de interação pensados em termos de estratégias de persuasão e de fazer-fazer, devemos prever a problemática do fazer-ser que ponha em jogo um outro tipo de relação entre os actantes, da ordem do contato, do sentir, em geral daquilo que chamamos de união.

Na leitura da escrita de professores sobre seus processos de significação para os encontros estéticos e práticas docentes em artes, foi necessário observar a complementariedade entre os regimes de sentido de junção e de união, para, como afirma Teixeira (2002), criar novos ritmos e novas narrativas, tecidas ao tempo em que se lê e escreve sobre a narração de experiências estéticas.

Enfim, a semiótica volta-se para o estudo das experiências estéticas que fazem parte do nosso viver rotineiro. Retoma a relevância da análise do dia a dia em sua dimensão estética, considerando o estésico, componente sensível da experiência cotidiana, como forma primeira de produção de sentido. Sob essa perspectiva, o sujeito e o objeto se reposicionam em um novo espaço relacional - um sentir o outro num movimento de significação que não está dado a priori. Sentir como está comovido, em coexistência, fazendo sentido ao sentir-se em inter-relação. Nessa perspectiva, a semiótica além de proporcionar instrumentos para a descrição dos objetos significantes pode, também, ser concebida como uma prática reflexiva e crítica de questionamentos sobre nós mesmos enquanto sujeitos em atividades de construção de sentidos. Na pesquisa em foco, a semiótica se tornou fundamental na para a leitura dos memoriais de formação e na construção das sínteses sobre a relação entre experiência estética e práticas docentes.

\section{Referências}

FABRI, P. Introdução. In: GREIMAS, A. J. Da Imperfeição. São Paulo: Hacker Editores, 2002. p. $95-111$. 
FERRY, L. Homo aestheticus: a invenção do gosto na era democrática. Tradução Eliana Maria de Melo Souza. São Paulo: Ensaio, 1994.

GREIMAS, A. J. Da Imperfeição. São Paulo: Hacker Editores, 2002.

GEIMAS, A. J.; COURTÉS, J. Dicionário de Semiótica. São Paulo: Contexto, 2008.

GREIMAS, A.J. Da Imperfeição. São Paulo: Companhia das Letras e Cores, 2017.

HUSSERL, E. Elemento para uma Elucidação Fenomenológica do Conhecimento. In: Edmund Husserl. São Paulo, SP: Nova Cultural, 2005. p. 25-30.

ISER, W. O ato da leitura: uma teoria do efeito estético. Tradução: Johannes Kretschmer. São Paulo: Ed. 34, 1996, v. 1.

ISER, W. O ato da leitura: uma teoria do efeito estético. Tradução: Johannes Kretschmer. São Paulo: Ed. 34, 1999, v. 2.

LACOSTE, J. A filosofia da arte. Tradução de Álvaro Cabral, Rio de Janeiro: Jorge Zahar Ed., 1997.

LANDOWSKI. E. De l'Imperfection, o livro do qual se fala. In: GREIMAS, A. J. Da Imperfeição. São Paulo: Hacker Editores, 2002a. P, 125 - 150.

LANDOWSKI, E. Modos de presença do visível. In: OLIVEIRA, Ana Claudia de. (org.). Semiótica plástica. São Paulo: Hacker Editores, 2004. p 97-112.

LANDOWSKI, E. Aquém ou além das estratégias, a presença contagiosa. Documentos de Estudo do Centro de Pesquisas Sociossemióticas, n.3. São Paulo: Edições CPS, 2005.

LANDOWSKI. E. Com Grimas. São Paulo: Estação das Letras e Cores, 2017.

MERLEAU-PONTY, M. Fenomenologia da Percepção. Tradução de Carlos Alberto Ribeiro de Moura. São Paulo: Martins Fontes, 1999.

MERLEAU-PONTY, M. A Natureza. Tradução de Álvaro Cabral. São Paulo: Martins Fontes, 2000.

TEIXIERA, L. Da Imperfeição: um marco nos estudos semióticos. In: Galáxia. n. 4, 2002. p. $257-261$.

TOURNIER, M. Sexta-Feira (ou os Limbos do Pacífico). Tradução de Fernando Botelho. São Paulo: Linoart/Círculo do Livro, 1990. 